\title{
Medium Optimization for the Production of Probiotic Lactobacillus acidophilus A12 Using Response Surface Methodology
}

\author{
Na-Kyoung Lee, Yeo-Lang Park, Ga Jin Choe, Hyo-Ihl Chang ${ }^{1}$, and Hyun-Dong Paik* \\ Division of Animal Life Science and Bio/Molecular Informatics, Konkuk University, Seoul 143-701, Korea \\ ${ }^{1}$ School of Life Science and Biotechnology, Korea University, Seoul 136-701, Korea
}

\begin{abstract}
Lactobacillus acidophilus A12 was isolated from chicken feces for use as an immunostimulating livestock probiotic. The purpose of this study was to optimize the production of L. acidophilus A12 using response surface methodology (RSM). Initially, the influence of growth medium was studied in terms of carbon sources (glucose, fructose, lactose, glycerol, sucrose, ethanol, and mannitol), nitrogen sources (beef extract, yeast extract, malt extract, and tryptone), and inorganic salts $\left(\mathrm{CaCl}_{2}, \mathrm{MgSO}_{4}, \mathrm{KH}_{2} \mathrm{PO}_{4},\left(\mathrm{NH}_{4}\right)_{2} \mathrm{SO}_{4}, \mathrm{FeSO}_{4}\right.$, and $\left.\mathrm{NaCl}\right)$. Through one factor-at-a time experiment, lactose, yeast extract, and $\mathrm{CaCl}_{2}$ were determined to be the best sources of carbon, nitrogen, and inorganic salt, respectively. The optimum composition was found to be $17.7 \mathrm{~g} / \mathrm{L}$ lactose, $18.6 \mathrm{~g} / \mathrm{L}$ yeast extract, and $0.9 \mathrm{~g} / \mathrm{L} \mathrm{CaCl}_{2}$. Under these conditions, a maximum cell density of $9.33 \mathrm{Log} \mathrm{CFU} / \mathrm{mL}$ was produced, similar to the predicted value.
\end{abstract}

Key words: Lactobacillus acidophilus, probiotics, chicken feces, medium optimization, response surface methodology

\section{Introduction}

Antibiotics have been used as feed additives to promote more productive livestock farming. However, the use of these growth-promoting substances has led to an imbalance of beneficial intestinal flora and the development of antibiotic-resistant bacteria pathogenic to animals or humans (Kummerer et al., 2003).

Probiotics have been used as an alternative to the use of antibiotics in animals and humans, and their efficiency as such in animals has been widely discussed (Benno and Mitsuoka, 1992; Clancy, 2003; Fernández et al., 2003; O'Sullivan, 2001). Probiotics are viable single or mixed cultures of microorganisms which, when given to animals or humans, beneficially affect the host by improving the properties of the indigenous microflora (Havenaar and Huis in't Veld, 1992). The bacteria most commonly associated with probiotic activity are lactobacilli and bifidobacteria, but other non-pathogenic organisms, such as Escherichia coli and the yeast, Saccharomyces boulardii, have been used (Shin et al., 1996, 1999; Sullivan and

\footnotetext{
*Corresponding author : Hyun-Dong Paik, Division of Animal Life Science and Bio/Molecular Informatics Center, Konkuk University, Seoul 143-701, Korea. Tel: 82-2-2049-6011, Fax: 82-2-455-3082, E-mail: hdpaik@konkuk.ac.kr
}

Nord, 2005; Xanthopoulos et al., 2000). Probiotic characteristics have been examined with regard to survival in gastric conditions, colonization of the intestine, reduction of lactose intolerance, prevention of antibiotic-induced diarrhea, cholesterol lowering effects, prevention of colon cancer, and stimulation of the immune system (Gibson and Roberfroid, 1995; Kim et al., 2006; Lee et al., 2007).

The mass production of probiotic cultures has been studied with regard to the optimization of medium composition (such as carbon, nitrogen, and minerals) and environmental factors (like $\mathrm{pH}$, temperature, agitation, etc.). In order to enhance the biomass yield probiotic cultures, an attempt was made to optimize the medium composition and process parameters and to characterize the cumulative and interactive effects on biomass production using response surface methodology (RSM). Optimization of growth medium is traditionally performed by varying one factor while keeping the other factors at constant levels. This technique is tedious when a large number of factors have to be investigated, whereas statistical experimental designs are a more efficient approach to deal with a large number of variables. Many reports have been published on the optimization of growth conditions for probiotic microorganisms. Sen and Swaminathan (1997) reported on the optimization of environmental conditions $(\mathrm{pH}$, temperature, agitation, and aeration) 
using RSM. Lejune et al. (1998) studied the effects of glucose concentration and incubation temperature using computer simulations. Escamilla et al. (2000) studied multiple nutritional (glucose, yeast extract, starch, etc.) and environmental parameters (temperature and $\mathrm{pH}$ ) in mixed cultures of Pediococcus pentosaceus and Lactobacillus acidophilus. The use of milk and cereals in growth media has also been investigated (Charalampopoulos et al., 2002; Gomes and Malcata, 1998). Camacho et al. (2009) studied the effects of temperature, $\mathrm{pH}$, and sodium chloride concentration on production of enzymes (esterase and lipase) and Cai and Zheng (2009) optimized keratinase production by Bacillus subtilis KD-N2 using RSM.

Lactobacillus acidophilus A12 was isolated from chicken feces. L. acidophilus A12 was highly resistant to artificial gastric juice, bile acid, and antibiotics. L. acidophilus A12 also produces immunostimulatory and antioxidiant substances (Lee et al., 2008). These results demonstrate the potential use of $L$. acidophilus A12 as a healthpromoting probiotic. In this study, the optimization of growth medium for the mass production of L. acidophilus A12 was carried out using a $2^{3}$ full factorial central composite design to determine the most productive sources of carbon, nitrogen and inorganic salts.

\section{Materials and Methods}

\section{Bacterial strain and culture media}

L. acidophilus A12 was cultured in lactobacilli MRS medium (Difco Laboratories, Detroit, MI, USA) at $37^{\circ} \mathrm{C}$. This strain was stored at $-70^{\circ} \mathrm{C}$ in MRS broth with $20 \%$ (v/v) glycerol.

\section{Production of probiotic $L$. acidophilus A12}

Seed culture was prepared by growing a single colony in $25 \mathrm{~mL}$ of MRS broth at $37^{\circ} \mathrm{C}$. Batch fermentation was carried out at $37^{\circ} \mathrm{C}$ in $500 \mathrm{~mL}$ Erlenmeyer flasks containing $250 \mathrm{~mL}$ of fermentation medium inoculated with $1 \%$ $(\mathrm{v} / \mathrm{v})$ seed culture.

\section{Enumeration of microbial cells}

One $\mathrm{mL}$ from each sample was serially diluted in sterile $0.1 \%(\mathrm{w} / \mathrm{v})$ peptone water, and the diluted samples were plated on lactobacilli MRS medium and incubated at $35^{\circ} \mathrm{C}$ for $24 \mathrm{~h}$. The plates were then counted and results recorded as colony forming units per milliliter $(\mathrm{CFU} / \mathrm{mL})$ of L. acidophilus A12.

\section{Optimization of growth medium}

The fermentation medium was studied in terms of carbon source, nitrogen source, and inorganic salts. Initially, the carbon sources tested were glucose, fructose, lactose, glycerol, saccharose, ethanol, and mannitol at $1 \%(\mathrm{w} / \mathrm{v})$ with $1 \%(\mathrm{w} / \mathrm{v})$ yeast extract. The nitrogen sources peptone, beef extract, yeast extract, malt extract, and tryptone were then studied at a $1 \%(\mathrm{w} / \mathrm{v})$ concentration, along with $1 \%(\mathrm{w} / \mathrm{v})$ optimized carbon source. Inorganic salts were then tested at a concentration of $0.1 \%(\mathrm{w} / \mathrm{v})$, and included $\mathrm{CaCl}_{2}, \mathrm{KH}_{2} \mathrm{PO}_{4},\left(\mathrm{NH}_{4}\right)_{2} \mathrm{SO}_{4}, \mathrm{NaCl}$, or $\mathrm{FeSO}_{4}$ in combination with optimized $1 \%(\mathrm{w} / \mathrm{v})$ carbon source and $1 \%(\mathrm{w} /$ v) nitrogen source.

\section{Central composite design}

Response surface methodology was performed to screen various medium components for the maximization of cell concentration. The response surface approach by central composite design with five coded levels was performed. For the three factors, this design consisted of a full $2^{3}$ factorial design with its eight points augmented with two replications of the center points (all factors at level 0) and the six star points, that is, points having for one factor an axial distance to the center of $\pm \alpha$, whereas the other two factors are at level 0 . The axial distance $\alpha$ was chosen to be 2 (Table 1).

\section{Statistical procedures}

The coefficient $b_{0}$ is the free or off-set term called the intercept. All results were analyzed by the software SAS 9.1. The model permitted evaluation of the effects of linear, quadratic and interactive terms of the independent variables on the chosen dependent variables. The optimum values of the selected variables were obtained by regression. RSM is an empirical technique employed for multiple regression analysis by using the data obtained. A central composite design coupled with a full second order polynomial model is used to acquire data to fit an empirical second order polynomial model. For three factors, the quadratic model takes the following form:

Table 1. Levels of independent variables in the experimental design

\begin{tabular}{llccccc}
\hline \hline \multirow{2}{*}{$\mathrm{X}_{\mathrm{n}}$} & \multirow{2}{*}{$\begin{array}{c}\text { Independent } \\
\text { variables }\end{array}$} & \multicolumn{6}{c}{ Levels } \\
\cline { 3 - 7 } & & -2 & -1 & 0 & 1 & 2 \\
\hline $\mathrm{X}_{1}$ & Lactose (\%) & 1.0 & 1.5 & 1.8 & 2 & 2.5 \\
$\mathrm{X}_{2}$ & Yeast extract (\%) & 0.5 & 1.0 & 1.4 & 1.8 & 2.0 \\
$\mathrm{X}_{3}$ & Calcium chloride (\%) & 0.0 & 0.1 & 0.2 & 0.3 & 0.4 \\
\hline
\end{tabular}




$$
\begin{aligned}
& \mathrm{Y}(\log \mathrm{CFU} / \mathrm{mL}) \\
& \begin{aligned}
= & \mathrm{b}_{0}+\mathrm{b}_{1} \mathrm{X}_{1}+\mathrm{b}_{2} \mathrm{X}_{2}+\mathrm{b}_{3} \mathrm{X}_{3}+\mathrm{b}_{12} \mathrm{X}_{1} \mathrm{X}_{2}+\mathrm{b}_{23} \mathrm{X}_{2} \mathrm{X}_{3} \\
& +\mathrm{b}_{13} \mathrm{X}_{1} \mathrm{X}_{3}+\mathrm{b}_{11} \mathrm{X}_{1}^{2}+\mathrm{b}_{22} \mathrm{X}_{2}^{2}+\mathrm{b}_{33} \mathrm{X}_{3}^{2}
\end{aligned}
\end{aligned}
$$

\section{Results and Discussion}

\section{Production of $L$. acidophilus A12}

A general cell growth curve for L. acidophilus A12 was determined in lactobacilli MRS medium before carrying out the one factor-at-a time optimization procedure (Fig. 1). The lag phase was approximately $2 \mathrm{~h}$ followed by the logarithmic phase from 2 to $8 \mathrm{~h}$. Cell growth was maintained for additional $8 \mathrm{~h}$. The maximum production of $L$. acidophilus A12 was observed at $16 \mathrm{~h}$ with a cell density of $8.23 \mathrm{Log} C F U / \mathrm{mL}$.

Effects of various carbon, nitrogen sources, and inorganic salts on cell growth

The factorial design for medium optimization addressed the carbon source, nitrogen source, and inorganic salts in that order. The effects of various carbon sources on cell growth are shown in Fig. 2. Lactose was found to be the best carbon source and thus was used as the carbon source in further experiments. In general, glucose is considered the best carbon source. Liu et al. (1999) showed glucose to be the best carbon source for the production of glutathione. However, glucose as the carbon source for $L$. acidophilus A12 resulted in a lower maximum cell density that with lactose, glycerol, mannitol, ethanol, or fructose. For L. acidophilus ATCC 4962, mannitol was determined to be the best carbon source for cholesterol removal and cell growth (Liong and Shah, 2005).

The effects of various nitrogen sources are shown in

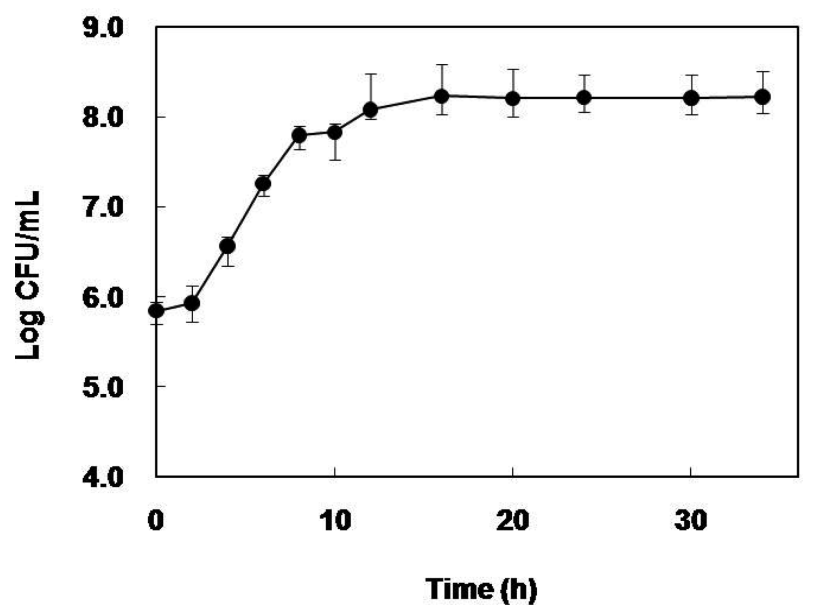

Fig. 1. Growth of L. acidophilus A12 in lactobacilli MRS medium.

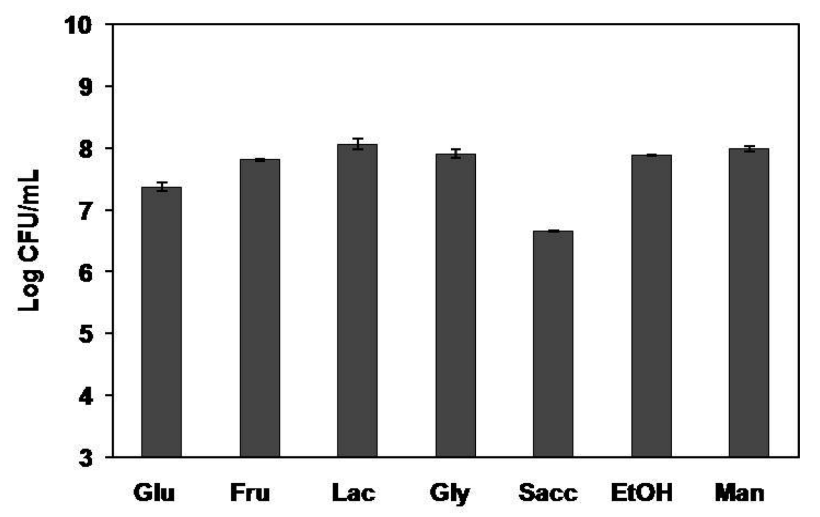

Fig. 2. Effect of various carbon sources with $1 \%$ yeast extract on $L$. acidophilus A12 cell concentration. Glu, glucose; Fru, fructose; Lac, lactose; Sacc, saccharose; EtOH, ethanol; Man, mannitol.

Fig. 3. The highest cell density was obtained when yeast extract was used as the nitrogen source, with a value of $8.15 \mathrm{Log} \mathrm{CFU} / \mathrm{mL}$. The relative cell densities for each nitrogen source in decreasing order were as follows: yeast extract $>$ peptone $>$ tryptone $>$ malt extract $>$ beef extract (Fig. 3). Therefore yeast extract was used as the carbon source for further experiments.

The effects of various inorganic salts are shown in Fig. 4. Calcium chloride and magnesium sulfate increased $L$. acidophilus A12 cell density relative to MRS medium. However, ammonium sulfate, sodium chloride, potassium phosphate had a negative effect on cell growth. No increase in cell growth was observed with the addition of ferrous sulfate (data not shown). Imbert and Blondeau (1998) reported similar results with the needless incorporation of iron to the growth medium of lactobacilli. Based on its positive effect on cell density, calcium chloride was used as the inorganic salt in further experiments. In sum-

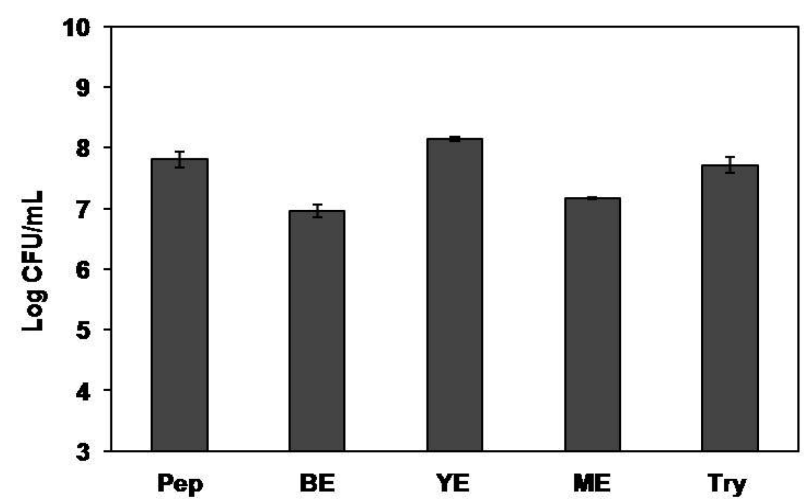

Fig. 3. Effect of various nitrogen sources with $1 \%$ lactose on L. acidophilus A12 cell concentration. Pep, peptone; BE, beef extract; YE, yeast extract; ME, malt extract; Try, tryptone. 


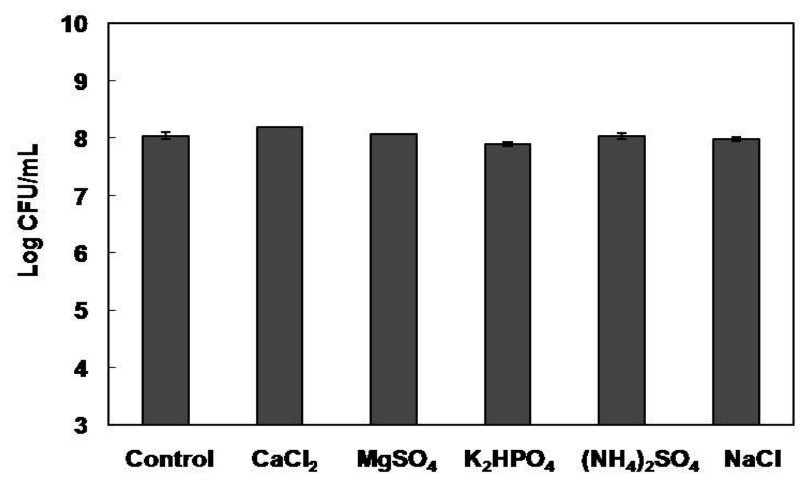

Fig. 4. Effect of various inorganic salts with $1 \%$ lactose and $1 \%$ yeast extract on $L$. acidophilus A12 cell concentration.

mary, the central composite design included lactose, yeast extract, and calcium chloride as the components of the growth medium.

\section{Production of $L$. acidophilus A12 using response surface methodology}

The results for experimental runs and calculated coefficients for cell concentrations are given in Tables 2 and 3, and the results of the second order response surface model fitting in the form of analysis of variance (ANOVA) are given in Table 4. The Fisher F-test (infinity) with a very low probability value $(\operatorname{Pr}>\mathrm{F}=<0.0001)$ demonstrates a very high significance for the regression models (Sen and Babu, 2005), and the correlation measures for the estimation of the regression equation are the determination coef-

Table 2. Experimental design and cell concentrations of the central composite design

\begin{tabular}{|c|c|c|c|c|}
\hline \multirow{2}{*}{$\begin{array}{l}\text { Exp. } \\
\text { No. }\end{array}$} & \multicolumn{3}{|c|}{ Medium composition $(\%)^{a}$} & \multirow{2}{*}{$\begin{array}{c}\text { Cell growth } \\
(\text { Log CFU/mL) }\end{array}$} \\
\hline & $\mathrm{X}_{1}$ & $X_{2}$ & $X_{3}$ & \\
\hline 1 & -1 & -1 & -1 & 8.48 \\
\hline 2 & -1 & -1 & 1 & 8.30 \\
\hline 3 & -1 & 1 & -1 & 9.22 \\
\hline 4 & -1 & 1 & 1 & 8.99 \\
\hline 5 & 0 & 0 & 0 & 8.40 \\
\hline 6 & 0 & 0 & 0 & 8.40 \\
\hline 7 & -2 & 0 & 0 & 8.71 \\
\hline 8 & 2 & 0 & 0 & 8.68 \\
\hline 9 & 0 & 2 & 0 & 9.05 \\
\hline 10 & 0 & -2 & 0 & 8.30 \\
\hline 11 & 0 & 0 & -2 & 9.23 \\
\hline 12 & 0 & 0 & 2 & 8.63 \\
\hline 13 & 1 & -1 & -1 & 8.46 \\
\hline 14 & 1 & -1 & 1 & 8.39 \\
\hline 15 & 1 & 1 & -1 & 9.30 \\
\hline 16 & 1 & 1 & 1 & 9.24 \\
\hline
\end{tabular}

${ }^{a} X_{1}$, lactose; $X_{2}$, yeast extract; $X_{3}$, calcium chloride.
Table 3. Least square fit and parameters for $L$. acidophilus A12 cell concentration

\begin{tabular}{lccc}
\hline \hline Model term $^{\mathrm{a}}$ & $\begin{array}{c}\text { Parameter } \\
\text { estimate }\end{array}$ & t-Value & $p$-Value \\
\hline Intercept & 11.9768 & 5.90 & 0.0011 \\
$\mathrm{X}_{1}$ & -2.2774 & -1.73 & 0.1339 \\
$\mathrm{X}_{2}$ & -1.7780 & -1.40 & 0.2103 \\
$\mathrm{X}_{3}$ & -8.1991 & -1.76 & 0.1293 \\
$\mathrm{X}_{1} \times \mathrm{X}_{1}$ & 0.4989 & 1.86 & 0.1127 \\
$\mathrm{X}_{2} \times \mathrm{X}_{1}$ & 0.2499 & 0.45 & 0.6679 \\
$\mathrm{X}_{2} \times \mathrm{X}_{2}$ & 0.7992 & 3.07 & 0.0218 \\
$\mathrm{X}_{3} \times \mathrm{X}_{1}$ & 1.0666 & 0.48 & 0.6466 \\
$\mathrm{X}_{3} \times \mathrm{X}_{2}$ & -0.1432 & -0.10 & 0.9216 \\
$\mathrm{X}_{3} \times \mathrm{X}_{3}$ & 13.5299 & 3.51 & 0.0127 \\
\hline
\end{tabular}

${ }^{\mathrm{a}} \mathrm{X}_{1}$, lactose; $\mathrm{X}_{2}$, yeast extract; $\mathrm{X}_{3}$, calcium chloride.

Table 4. Analysis of variance (ANOVA) for L. acidophilus A12 cell concentration

\begin{tabular}{lccccc}
\hline \hline $\begin{array}{l}\text { Sources of } \\
\text { variations }\end{array}$ & DF & $\begin{array}{c}\text { Sum of } \\
\text { squares }\end{array}$ & $\begin{array}{c}\text { Mean } \\
\text { square }\end{array}$ & $\begin{array}{c}\mathrm{F} \\
\text { Value }\end{array}$ & $\operatorname{Pr}>\mathrm{F}$ \\
\hline Model & 5 & 0.149585 & 0.029917 & Infinity & $<0.0001$ \\
Error & 1 & 0 & 0 & & \\
Corrected total & 6 & 0.149585 & 0.024931 & & \\
\hline
\end{tabular}

Root $\mathrm{MSE}=0.16 ; \mathrm{CV}=1.81 \% ; \mathrm{R}^{2}=0.93$.

ficients $\left(\mathrm{R}^{2}=0.93\right)$. The coefficients of variation $(\mathrm{CV}=$ $1.81 \%$ ) indicate a high precision and reliability of the experiments. The predicted regression equation as a function of the coded values of critical variables is as follows:

$$
\begin{aligned}
\mathrm{Y}= & 11.98-2.28 \mathrm{X}_{1}-1.78 \mathrm{X}_{2}-8.20 \mathrm{X}_{3}+0.25 \mathrm{X}_{1} \mathrm{X}_{2} \\
& +1.07 \mathrm{X}_{1} \mathrm{X}_{3}-0.14 \mathrm{X}_{2} \mathrm{X}_{3}+0.50 \mathrm{X}_{1}^{2}+0.80 \mathrm{X}_{2}^{2} \\
& +13.53 \mathrm{X}_{3}^{2}
\end{aligned}
$$

In Table 4, it is evident that the quadratic main effects of yeast extract $(p=0.0218)$ and calcium chloride $(p=$ 0.0127 ) are more significant than their respective first order effects, though the cross product regressions are not significant ( $p>0.6$ ). In this function, calcium chloride was the most important constituent, as evident from its quadratic main effect. Yeast extract at concentrations of 0.5$2 \%(\mathrm{w} / \mathrm{v})$ showed positive effects (Fig. 5), however lactose at concentrations of $0.25-3 \%(\mathrm{w} / \mathrm{v})$ had negative effects (Fig. 5).

The optimal medium for the production of L. acidophilus $\mathrm{A} 12$ was determined to contain $17.7 \mathrm{~g} / \mathrm{L}$ lactose, 18.6 $\mathrm{g} / \mathrm{L}$ yeast extract, and $0.9 \mathrm{~g} / \mathrm{L}$ calcium chloride resulting in a maximal cell density of $9.33 \mathrm{Log} \mathrm{CFU} / \mathrm{mL}$. Fermentation was carried out in the optimized medium at $35^{\circ} \mathrm{C}$, with $1 \%(\mathrm{v} / \mathrm{v})$ seed culture (Fig. 6). This resulted in $13.37 \%$ higher production of $L$. acidophilus A12 in the 

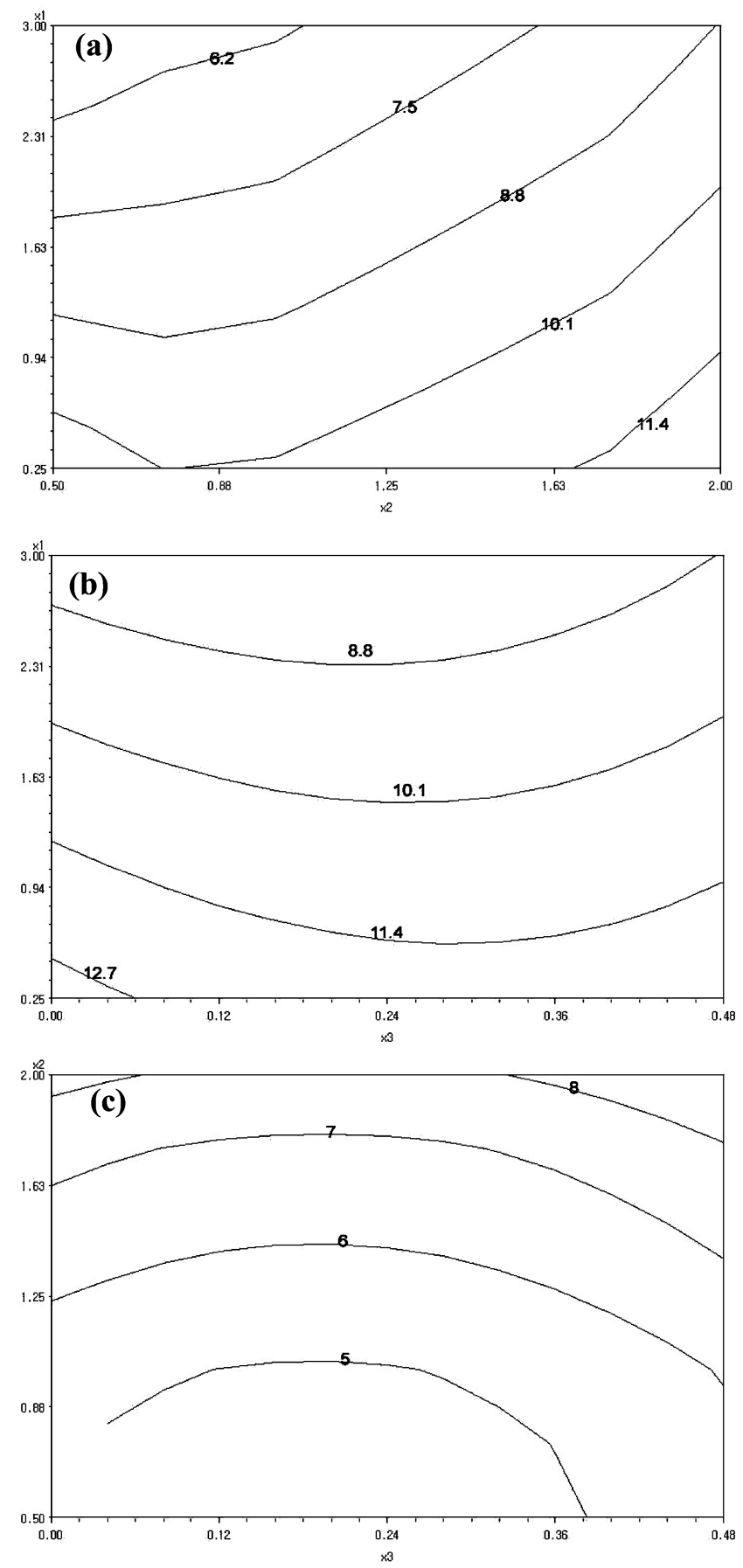

Fig. 5. Contour plot of cell concentration: effect of (a) lactose and yeast extract; (b) lactose and calcium chloride; (c) yeast extract and calcium chloride.

optimized medium relative to MRS medium. These data are in close agreement with the model predictions.

\section{Acknowledgements}

This study was funded by research grants from Biogreen 21 Program (2005-0108) and supported by Priority Research Centres Program throuth the National

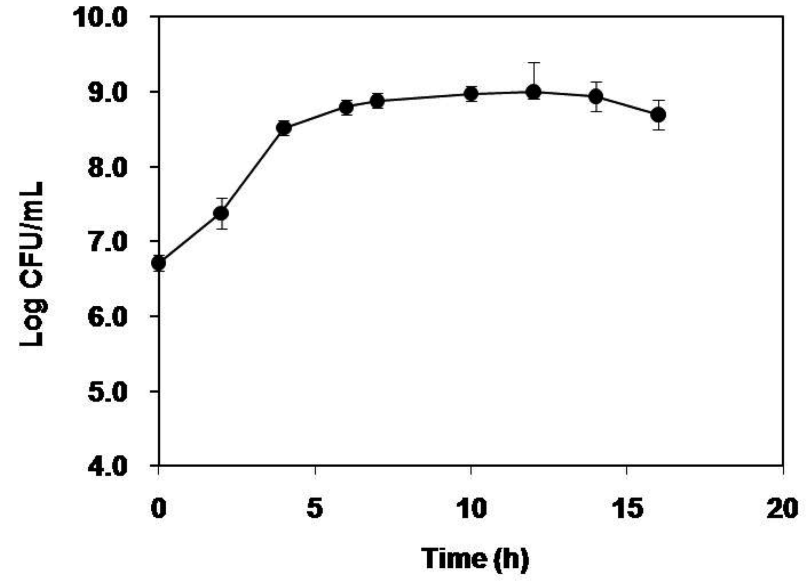

Fig. 6. Growth of L. acidophilus A12 in optimized medium.

Research Foundation of Korea (2009-0093824), Korea.

\section{References}

1. Benno, Y. and Mitsuoka, T. (1992) Impact of Bifidobacterium longum on human fecal microflora. Microbiol. Immunol. 36, 683-694.

2. Charalampopoulos, D., Pandiella, S. S., and Webb, C. (2002) Growth studies of potentially probiotic lactic acid bacteria in cereal-based substrates. J. Appl. Microbiol. 92, 851-859.

3. Cai, C. and Zheng, X. (2009) Medium optimization for keratinase production in hair substrate by a new Bacillus subtilis KD-N2 using response surface methodology. J. Ind. Microbiol. Biotechnol. 36, 875-883.

4. Clancy, R. (2003) Immunobiotics and the probiotic evolution. FEMS Immunol. Med. Microbiol. 38, 9-12.

5. Camacho, R. M., Mateos, J. C., González-Reynoso, O., Prado, L. A., and Córdova, J. (2009) Production and characterization of esterase and lipase from Haloarcula Marismortui. J. Ind. Microbiol. Biotechnol. 36, 901-909.

6. Escamilla, M. L., Valdés, S. E., Soriano, J., and Tomasini, A. (2000) Effect of some nutritional and environmental parameters on the production of diacetyl and on starch consumption by Pediococcus pentosaceus and Lactobacillus acidophilus in submerged cultures. J. Appl. Microbiol. 88, 142-153.

7. Fernández, M. F., Boris, S., and Barbés, C. (2003) Probiotic properties of human lactobacilli strains to be used in the gastrointestinal tract. J. Appl. Microbiol. 94, 449-445.

8. Gibson, G. R. and Roberfroid, M. B. (1995) Dietary modulation of the human colonic microbiota: introducing the concept of prebiotics. J. Nutr. 125, 1401-1412.

9. Gomes, A. M. P. and Malcata, F. X. (1998) Use of small ruminants' milk supplemented with available nitrogen as growth media for Bifidobacterium lactis and Lactobacillus acidophilus. J. Appl. Microbiol. 85, 839-848.

10. Havenaar, R. and Huis in't Veld, J. H. J. (1992) Probiotics: a general view. In: Wood, B. J. B., editor. The lactic acid bacteria in health and disease. Elsevier, Amsterdam, pp. 1-200. 
11. Imbert, M. and Blondeau, R. (1998) On the iron requirement of lactobacilli grown in chemically defined medium. Curr. Microbiol. 37, 64-66.

12. Kim, J.-T., Jung, H.-Y., Lee, N.-K., Rhim, S.-L., and Paik, H.-D. (2006) Isolation, identification, and probiotic properties of Lactobacillus reuteri HY701 from human feces. Food Sci. Biotechnol. 15, 677-682.

13. Kummerer, K. (2003) Significance of antibiotics in the environment. J. Antimicrob. Chemother. 52, 5-7.

14. Lee, N.-K., Noh, J.-E., Choi, G.-H., Park, E., Chang, H.-I., Yun, C.-W., Kim, S.-W., Kang, C.-W., Yoon, Y.-C., and Paik, H.-D. (2007) Potential probiotic properties of Lactococcus lactis NK34 isolated from Jeotgal, a Korean fermented food. Food Sci. Biotechnol. 15, 227-231.

15. Lee, N.-K., Yun, C.-W., Kim, S.-W., Chang, H.-I., Kang, C.W., and Paik, H.-D (2008) Screening of lactobacilli derived from chicken feces and partial characterization of Lactobacillus acidophilus A12 as animal probiotics. J. Microbiol. Biotechnol. 18, 338-342.

16. Lejeune, R., Callewaert, R., Crabbé, K., and De vuyst, L. (1998) Modelling the growth and bacteriocin production by Lactobacillus amylovorus DCE 471 in batch cultivation. $J$. Appl. Microbiol. 84, 159-168.

17. Liong, M. T. and Shah, N. P. (2005) Optimization of cholesterol removal, growth and fermentation patterns of Lactobacillus acidophilus ATCC 4962 in the presence of mannitol, fructo-oligosaccharide and inulin: a response surface methodology approach. J. Appl. Microbiol. 98, 1115-1126.
18. Liu, C. H., Hwang, C. F., and Liao, C. C. (1999) Medium optimization for glutathione production by Saccharomyces cerevisiae. Process Biochem. 34, 17-23.

19. O’Sullivan, G. C. (2001) Probiotics. Brit. J. Surg. 88, 161162.

20. Sen, R. and Swaminathan, T. (1997) Application of responsesurface methodology to evaluate the optimum environmental conditions for the enhanced production of surfactin. Appl. Microbiol. Biotechnol. 47, 358-363.

21. Sen, R. and Babu, K. S. (2005) Modelling and optimization of the process conditions for biomass production and sporulation of a probiotic culture. Process Biochem. 40, 25312538.

22. Shin, M. S., Kim, Y. J., Bae, H. S., and Baek, Y. J. (1996) Effects of the lactic acid bacteria administration on fecal microflora and putrefactive metabolites in healthy adults. Kor. J. Microbiol. Biotechnol. 24, 254-260.

23. Shin, M. S., Kim, H. M., Kim, G. T., Huh, C. S., Bae, H. S., and Baek, Y. J. (1999) Selection and characteristics of Lactobacillus acidophilus strain from Korean feces. Kor. J. Food Sci. Technol. 31, 495-501.

24. Sullivan, Å. and Nord, C. E. (2005) Probiotics and gastrointestinal disease. J. Int. Med. 257, 78-92.

25. Xanthopoulos, V., Litopoulou-Tzanetaki, E., and Tzanetakis, N. (2000) Characterization of Lactobacillus strains from infant faeces as dietary adjuncts. Food Microbiol. 17, 205215 .

(Received 2009.9.10/Revised 2010.3.8/Accepted 2010.3.11) 